\title{
REVIEWS
}

\section{How will HPV vaccines affect cervical cancer?}

\section{Richard Roden ${ }^{* \ddagger \S}$ and T.-C. Wu ${ }^{* \ddagger \S \uparrow}$}

Abstract | Cancer of the uterine cervix is the second largest cause of cancer deaths in women, and its toll is greatest in populations that lack screening programmes to detect precursor lesions. Persistent infection with 'high risk' genotypes of human papillomavirus (HPV) is necessary, although not sufficient, to cause cervical carcinoma. Therefore, HPV vaccination provides an opportunity to profoundly affect cervical cancer incidence worldwide. A recently licensed HPV subunit vaccine protects women from a high proportion of precursor lesions of cervical carcinoma and most genital warts. Here we examine the ramifications and remaining questions that surround preventive HPV vaccines.
Squamous intraepithelial lesion

The Bethesda System of cytological diagnosis uses lowgrade squamous intraepithelial lesion (LSIL) for lesions previously classified as koiliocytic atypia and CIN1, and high-grade squamous intraepithelial lesion (HSIL) for lesions formerly designated as $\mathrm{CIN2/3.}$

Cervical intraepithelial neoplasia

The CIN terminology divides cervical cancer precursors into three histological classes: CIN1 (mild dysplasia), CIN2

(moderate dysplasia) and CIN3 (severe dysplasia or carcinoma in situ). 'High-grade' SIL is synonymous with CIN2/3.

Departments of Pathology*, Oncology ${ }^{\ddagger}$, Obstetrics and Gynecology ${ }^{\S}$, Molecular Microbiology and Immunology', The Johns Hopkins University. Baltimore, Maryland 21231, USA

Correspondence to R. R. and T.-C.W.

e-mails: roden@jhmi.edu; wutc@jhmi.edu

doi:10.1038/nrc1973
Epidemiological and laboratory studies overwhelmingly support a necessary role for persistent human papillomavirus (HPV) infection and transcription in cervical carcinogenesis $^{1,2}$ (BOX 1). Importantly, HPV infection alone is not sufficient for cervical carcinogenesis, and additional steps occur over one or two decades. HPV is probably the most common sexually transmitted disease. It is estimated that the worldwide age-standardized prevalence of current HPV infection is $10.5 \%$ (95\% CI 9.9-11.0) of women; the prevalence varies about 20 -fold between different regions, from 1.4\% (95\% CI 0.5-2.2) in Spain to 25.6\% (95\% CI 22.4-28.8) in Nigeria ${ }^{3}$.

More than 100 different HPV genotypes have been defined, of which about 40 infect the genital mucosa ${ }^{4}$. These genital HPV types are classified into low or high risk by their propensity to cause cervical cancer. Low-risk HPV types, typified by HPV6 and HPV11, produce benign genital warts, condyloma accuminata. High-risk types, most notably HPV16 and HPV18, are the aetiological agent of cervical cancer. Although HPV 16 accounts for about half of all cervical cancers, and HPV 18 an additional 20\%, there are at least 15 known oncogenic HPV types (FIG. 1). Fortunately, infection by high-risk type HPV is not sufficient to cause cervical cancer ${ }^{1}$. Most high-risk type HPV infections are subclinical. Only a minority of high-risk HPV infections produce squamous intraepithelial lesions (SILs, also called cervical intraepithelial neoplasia (CIN) and previously referred to as dysplasia $)^{5}$, and a small fraction of SILs lead to cervical cancer (FIG. 2). Natural history studies show that most HPV infections and HPV-related intraepithelial lesions (dysplasias) are cleared, probably by immune mechanisms ${ }^{6,7}$.
Cervical cancer deaths in the United States were limited to 3,700 (Surveillance Epidemiology and End Results (SEER) database) during 2005, which reflects the success of cytological screening by Pap smears (BOX 2), although adenocarcinomas of the cervix are more challenging to detect with this approach. Progression to cancer can usually be prevented by the ablation or surgical removal of high-grade precursor lesions (HSIL or CIN2/3). In 2005, more than 60 million Pap smears were performed in the United States, and it is estimated that such screening programmes and intervention have reduced the incidence of cervical cancer by $\sim 80 \%$ in the United States, but at a cost of more than US $\$ 6$ billion a year.

Despite this success, many women do not have access to screening. This problem is most acute in disadvantaged minorities in developed nations, in cultures that do not accept the screening process and in countries that are remote and lack the resources for screening programmes. Consequently, the impact of cervical cancer is greatest in these countries; the latest global estimates (from 2002) are 493,000 new cervical cancer cases each year, and 274,000 deaths, $80 \%$ of which occur in developing countries ${ }^{8}$.

Vaccination traditionally represents the most costeffective approach to combat infectious disease. Two approaches to vaccination, or a combination of both, can be considered: prophylactic (preventive) and therapeutic immunization. Prophylactic vaccination of healthy individuals against the aetiological agent protects against acquisition of the disease, but confers some risk to otherwise healthy patients and requires massive programmes to vaccinate a significant fraction of the population. Comprehensive prophylactic vaccination 


At a glance
- Cervical cancer is the second largest cause of cancer deaths in women worldwide.
Persistent infection with human papillomavirus (HPV) is necessary but not sufficient to
cause cervical cancer, and preventing HPV infection can prevent the disease.
- Cervical cancer is currently prevented by Pap smears and/or HPV testing and ablation
of high-grade squamous intraepithelial lesions (HSILs). However, the US Food and
Drug Administration approved a preventive HPV vaccine on 8 June 2006 for the
immunization of women between 9-26 years of age.
- HPV virus-like particle (VLP) vaccines based on the major capsid antigen L1 show very
high protective efficacy and good safety profiles so far, and therefore have the
potential to globally affect cervical cancer. However, guidelines on when to vaccinate
and whether a boost is necessary depend on the duration of protection, which
remains to be determined.
- Protection with the L1 VLP vaccine shows strong HPV type restriction, therefore highly
valent vaccines are required for broad protection. Minor capsid antigen L2-based
vaccines might have potential for broad coverage with a monovalent vaccine.
- There is little evidence that HPV VLP vaccines have therapeutic activity in patients,
and the continued development of therapeutic vaccines is warranted.
- The influence of herd immunity through the vaccination of men is likely to be
beneficial, but it will have a relatively modest effect on cervical cancer rates
compared with the broad vaccination of women. However, trials to evaluate the HPV
vaccine in men are ongoing, as men do contract genital warts and HPV-related
cancers at other sites in addition to transmitting HPV to women.
- Societal response is developing and will have an effect on the introduction of HPV
vaccines.
- Cervical cancer normally occurs in developing countries that lack the resources for
screening. The development of alternative HPV vaccines that are low cost and heat
stable will be important for the worldwide introduction of the vaccine. Approaches to
needle-free vaccination are also being tested.
susceptibility to HPV-related cancer. It is important to determine whether these
patients will respond less well to HPV vaccines.

Prophylactic and therapeutic vaccines Prophylactic vaccines are given to healthy patients to prevent disease before exposure to the aetiological agent. By contrast, therapeutic vaccines are given to patients to cure or ameliorate an existing disease.

Hepatitis $B$ virus vaccine Prevents hepatitis B disease and its sequelae, such as hepatocellular carcinoma (liver cancer). It is the first anticancer vaccine.

Major and/or minor capsid antigens $\mathrm{L} 1$ and $\mathrm{L} 2$ The constituents of the papillomavirus capsid. L1 and L2 are 'late' proteins.

Virus-like particle

A non-infectious capsid-like structure devoid of the viral

nucleic acid that comprises all or a subset of the capsid

antigens and resembles native virions, both morphologically and immunologically. has historically proven most successful in disease reduction. The US Food and Drug Administration (FDA) approved a preventive HPV vaccine on 8 June 2006 for the immunization of women between 9-26 years of age ${ }^{9}$, and a second vaccine is in phase III trials. By contrast, the ability to test for high-risk HPV DNA or screen for intraepithelial lesions, and the high rates of spontaneous clearance, suggest the possibility of therapeutic vaccination restricted to infected individuals. Although the notion of vaccinating only those patients with disease is attractive, there are currently no therapeutic HPV vaccines that have shown high efficacy in clinical trials. The HPV preventive vaccines have generated considerable interest, and are the focus of this Review.

\section{Development of preventive HPV vaccines}

Lessons from animal models. Studies of animal papillomaviruses have been very important in the development of HPV vaccines because HPV only replicates in humans ${ }^{10}$. Vaccination with both animal papillomavirus and HPV virions induces neutralizing antibody responses ${ }^{11-15}$. Further, formalin-inactivated virion vaccines protect animals against the natural acquisition of warts ${ }^{16}$ (but protection is restricted by papillomavirus type $\left.{ }^{17}\right)$. HPV is difficult to culture, and its genome contains three potent oncogenes. Therefore, an inactivated HPV vaccine could not be considered for use in humans. Rather, the safety profile and efficacy of the hepatitis B virus vaccine galvanized interest in developing an HPV vaccine based on the major and/or minor capsid antigens, L1 and L2 respectively.

Early studies indicated that L1-protective epitopes were probably dependent on native conformation, as vaccination with denatured L1 was poorly effective ${ }^{18,19}$. The expression of recombinant L1 in mammalian ${ }^{20,21}$, insect ${ }^{22,23}$, yeast ${ }^{24}$ and even bacterial cells ${ }^{25}$ generated virus-like particles (VLPs) that were morphologically similar to native virions. Importantly, these recombinant L1 proteins were immunologically very similar to native virions $^{22,23,26}$. The parenteral vaccination of animals with either L1 VLPs or native virions induced high titres of neutralizing serum immunoglobulin G (IgG), and protected from papillomavirus challenge at mucosal and cutaneous sites. Similar studies in different animal papillomavirus models showed that L1 VLPs are immunogenic and protective, and that protection is mediated by neutralizing serum antibodies ${ }^{18,27-29}$.

Despite the consistent protective efficacy of L1 VLPs in preclinical studies, there was considerable trepidation in translating this vaccine to humans because animal models do not involve sexual transmission. High-risk $\mathrm{HPV}$ replicates in the genital mucosal epithelium, which suggests that local immunity might be important for protection. Therefore, it was unclear whether the induction of neutralizing serum antibodies would provide protection, particularly as the transudation of IgG into the genital tract varies in efficiency throughout the menstrual cycle ${ }^{30,31}$.

Efficacy studies of HPV L1 VLP vaccines in humans. Efficacy trials of HPV-preventive vaccines comprising mixtures of L1 VLPs of up to four of the most medically relevant HPV genotypes (HPV16 and HPV18 for cervical cancer, and HPV6 and HPV11 for benign genital warts) have been reported (TABLE 1). The quadrivalent HPV (types 6, 11, 16 and 18) L1 VLP recombinant vaccine (Gardasil) produced by Merck has been approved by the FDA. A second vaccine that contains L1 VLPs of HPV types 16 and 18 (Cervarix) produced by GlaxoSmithKline is in phase III trials. The L1 VLPs for the Merck vaccine are produced in recombinant yeast and formulated in the adjuvant alum, and those for the GlaxoSmithKline vaccine are produced using insect cells infected with recombinant baculovirus and formulated in the proprietary adjuvant ASO4. Trials to date have used three intramuscular doses to assess the safety and efficacy of candidate HPV vaccines. The crucial efficacy endpoints have been protection from HPV-related SIL and persistent HPV infection by the HPV types used to derive the vaccine.

Two phase I clinical studies published in 2001 showed that vaccination with HPV L1 VLPs produced using baculovirus is well tolerated and highly immunogenic $^{32,33}$. The HPV16 L1 VLP vaccine induced neutralizing serum antibodies even without adjuvant, and most recipients achieved serum antibody titres that were about 40-fold higher than the level observed in natural infection $^{32,33}$. Similar findings were obtained with L1 VLPs 


\section{Box 1 | Does HPV cause cervical cancer?}

Is 'high-risk' human papillomavirus (HPV) a true aetiological agent of cervical cancer or a harmless passenger? Causation can be examined by addressing Koch's postulates as modified by Rivers for viral diseases. Several of these six postulates cannot be tested ethically in patients. Therefore, we must rely heavily on epidemiological data ${ }^{105}$ and laboratory studies to provide the mechanistic underpinning of HPV transformation ${ }^{106,107}$. Animal papillomavirus models are also informative; notably, seminal work with cottontail rabbit papillomavirus (CRPV) that induces squamous cancer in a subset of domestic rabbits ${ }^{108}$. Epidemiological and laboratory studies overwhelmingly support a necessary, but not sufficient, role for persistent high-risk HPV-type infection in cervical carcinogenesis ${ }^{1,2}$. A drop in cervical cancer rates following a reduction in HPV infections would be definitive proof.

\section{Postulate \\ Isolation of virus from diseased hosts}

Cultivation in host cells

Retain infectivity after

filtering away bacteria

Production of comparable disease in the original host species or a related species

Re-isolation of the virus

Detection of a specific immune response to the virus

\section{Experimental and epidemiological evidence}

HPV DNA is detected in $99.7 \%$ of cervical cancer specimens $^{109}$

HPV replicates in organotypic cultures of human keratinocytes ${ }^{110}$. High-risk HPV immortalizes primary keratinocytes ${ }^{111}$, and cervical cancer cells cannot survive after the blockade of E6 and E7 expression ${ }^{112}$

Shown for CRPV in rabbits ${ }^{11}$

HPV only productively infects humans, and therefore animal papillomaviruses are frequently used as models (for example, CRPV, which induces squamous-cell cancer in domestic rabbits) ${ }^{11,113}$

Transformation is associated with an absence of epithelial differentiation and papillomavirus genome integration, preventing virion production and consequently 'classical' re-isolation ${ }^{114}$. Although CRPV infection of domestic rabbits does not produce the virus, the CRPV genome is present in squamous-cell cancers

HPV capsid-specific serum immunoglobulin G is associated with a high relative risk for cervical cancer ${ }^{115}$
Keratinocytes

Epidermal cells that produce keratin.

E6 and E7

The two most significant viral oncoproteins in HPV-related cancer.

Cottontail rabbit papillomavirus

An important animal papillomavirus used for vaccine studies. Other animal models include rabbit oral papillomavirus, bovine papillomavirus and canine oral papillomavirus. derived from other HPV types, and optimal dosing was established ${ }^{3-36}$. In a landmark study, Koutsky et al. showed that vaccination three times with HPV16 L1 VLPs formulated in the adjuvant alum provided $100 \%$ protection $(95 \% \mathrm{CI}, 90-100 ; P<0.001)$ from the natural acquisition of persistent HPV16 infection over an average of 17.4 months $^{37}$ (TABLE 1). Importantly, all nine cases of incident HPV16-related CIN were confined to the placebo group, indicating that vaccination protects against HPV-related disease. This high degree of efficacy of L1 VLP vaccines for protection against persistent infection and cervical disease relating to the same HPV type infection has also been shown in other studies ${ }^{38-41}$.

\section{Immune correlates of protection}

The identification of the relevant immune parameters that correlate with protection is important, both to assess whether the vaccination of an individual is successful and inform development of second generation HPV vaccines. Historically, the most consistent correlate of protection for licensed vaccines has been the measurement of serum neutralizing antibodies ${ }^{42}$. The induction of VLP-specific serum antibodies is associated with protection in both animal and clinical studies ${ }^{18,27-29,37-39}$. The measurement of
HPV-neutralizing antibodies in serum has, so far, correlated strongly with L1 VLP-specific indirect enzyme-linked immunosorbent assay (ELISA) because the neutralizing epitopes are immunodominant and conformational ${ }^{22}$. In addition, the transfer of immune sera from vaccinated animals to naïve animals is sufficient to confer protection against experimental animal papillomavirus infection ${ }^{18,27}$.

Neutralizing antibodies can coat virions and prevent their binding to cell surfaces ${ }^{43}$. However, additional mechanisms of neutralization that occur after the binding of the virion to the cell surface are also probably important ${ }^{44}$. Protection might be mediated through the transudation of neutralizing IgG from the serum to the genital $\operatorname{tract}^{45}$ (FIG. 2). Epithelial damage is presumed to facilitate the passage of HPV across the upper layers of the squamous epithelium to reach the basal epithelium and initiate infection. Therefore, sterilizing immunity might occur through the direct exudation of serum antibodies at the site of microtraumas that occur during intercourse.

Importantly, the minimal protective titre and the possible contribution of cellular immunity remain to be defined. Immune-cell-mediated clearance of viral infection in protection from disease could complicate the use of serum antibody titres to predict protection. The identification of the relevant immune parameters that correlate with protection will also facilitate the identification of patients in need of additional boosts or rare non-responders.

\section{How to overcome type-restricted protection?}

Animal studies have indicated that vaccination with L1 VLPs is protective against the same (homologous) papillomavirus type as that from which the VLPs were derived, but not for different (heterologous) papillomavirus types ${ }^{18}$. Similarly, women who were vaccinated with HPV16 L1 VLPs were completely protected from HPV16-related CIN, but equivalent numbers of CIN lesions related to HPV types other than HPV16 occurred in the vaccine and placebo groups ${ }^{37}$. Type-restricted protection occurred in other trials (FIG. 3). This type restriction is also reflected in the specificity of the neutralizing antibodies induced by VLP vaccination ${ }^{46}$.

One option for broad coverage is to develop a highly multivalent vaccine, and this has been done with a number of licensed vaccines against other agents. However, this raises the cost and complexity of manufacture with progressively decreasing returns. Nevertheless, the quadrivalent Gardasil vaccine is highly effective at protecting against external genital warts and CINs related to the homologous types ${ }^{39}$. This suggests that VLPs of additional types might be added, as vaccination with mixtures of multiple types of VLPs does not significantly interfere with responses compared with vaccination with individual types. It has been suggested that a vaccine comprising the eight most prevalent HPV types detected in cancer might be required for $>90 \%$ protection against cervical cancer (FIG. 1) ${ }^{47}$. The oncogenic HPV types that are present in different parts of the world are relatively consistent, which suggests that such a multivalent vaccine would be useful worldwide ${ }^{3}$. 


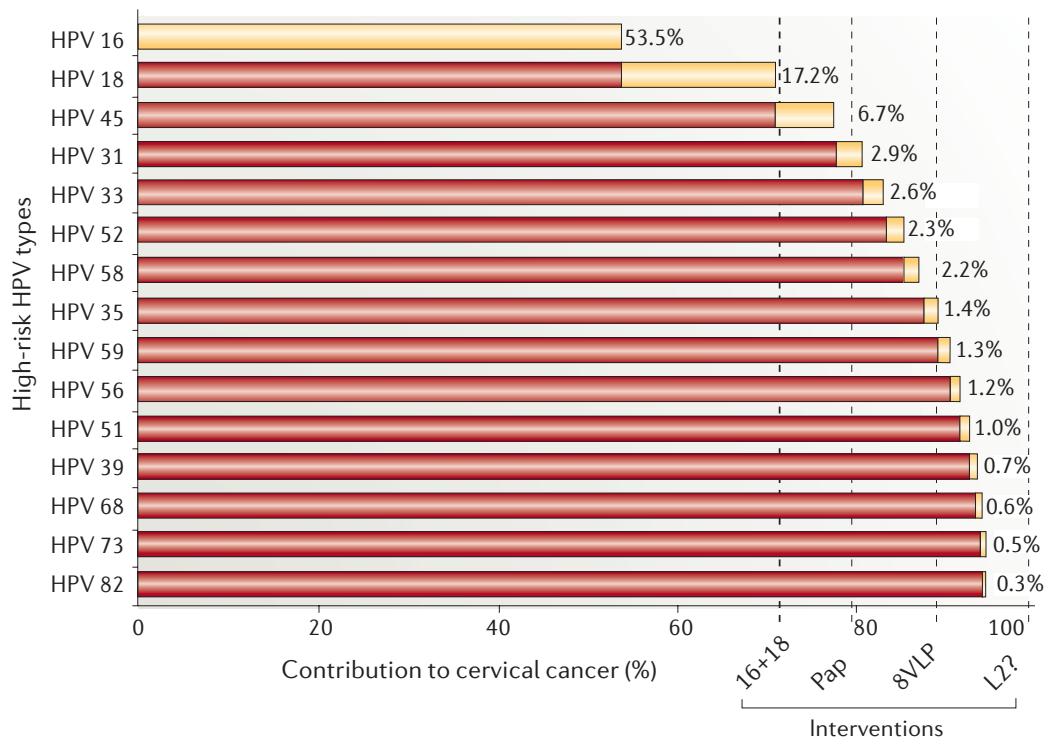

Figure 1 | The cumulative frequency of HPV genotypes present in cervical cancer and the potential impact of interventions. The subset of human papillomavirus (HPV) genotypes that are associated with most cervical cancers and deemed 'high-risk' genotypes are shown. Yellow bars and percentages next to each bar indicate the percentage of cervical cancer cases attributed to each HPV genotype, and red bars indicate the cumulative percentage of cases. A type-restricted vaccine comprising HPV16 and HPV18 L1 virus-like particles (VLPs) (16 and 18) would provide protection against $\sim 70 \%$ of cervical cancers. It is estimated that Pap screening and intervention has reduced the incidence of cervical cancer by $\sim 80 \%$. Similarly, the HPV16 and HPV1 18 L1 VLP vaccine formulated in ASO 4 might protect against $~ 80 \%$ of cancers owing to crossprotection against the most closely related types to HPV16 and HPV18 (REF. 40). Munoz et al. predict that a type-specific octavalent HPV VLP vaccine (8VLP) would provide $~ 90 \%$ protection ${ }^{47}$, although type-specificity is unlikely to be absolute so protection might be better. L2 vaccines induce broadly cross-neutralizing antibodies and are protective in animal models, but have not been tested in patients for the prevention of HPV infection. As $\mathrm{HPV}$ is associated with $99.7 \%$ of cervical cancers ${ }^{109}$, several groups are examining the potential of L2-based vaccines for broad protection against oncogenic HPV genotypes (L2?). Image modified with permission from REF. $47^{\odot}(2004)$ Wiley.

Koch's postulates as modified by Rivers for viral diseases

Koch's postulates are criteria used to judge whether a given microbe causes a given disease In 1937, Rivers expanded on Koch's original postulates and proposed six criteria that should be met to establish whether or not a virus is the causative agent of a disease.

Parenteral vaccination Vaccine given by intravenous, intramuscular, or subcutaneous injection.

Neutralizing serum antibodies

Antibodies present in blood plasma after clotting that are able to inactivate viral infection
Subtle variations in VLP production or adjuvants could also provide slightly broader coverage. The GlaxoSmithKline vaccine that contains HPV16 and HPV18 L1 VLPs produced in insect cells and formulated in ASO4 (REFS 38,40) was effective for protection against both persistent infection and CIN related to HPV16 and HPV18 (FIG. 3b). HPV16 and HPV31, and HPV 18 and HPV45 have very closely related genotypes $^{20}$ (>85\% sequence identity), and show low-level cross-neutralization ${ }^{46,48-50}$. Vaccination with HPV16 and HPV18 L1 VLPs provided 94\% (95\% CI 63.9-99.9) protection against HPV45 and 54\% (95\% CI 11.5-77.7) against HPV31, although protection against HPV33, HPV52 and HPV58, which are less closely related, was not significant ${ }^{40}$. These and other data suggest that the neutralization assay is predictive of protection ${ }^{46,48-50}$. Also, antibody cross-reaction between HPV 16 and HPV 31 or HPV 18 and HPV45 is two orders of magnitude less than reactivity to the homologous type ${ }^{49,50}$, which suggests that very low antibody titres are protective.

An alternative approach to highly multivalent vaccine preparations for broad protection is the identification of a conserved and cross-protective antigen. Vaccination with the minor capsid protein $\mathrm{L} 2$ is protective in animal models $s^{51-53}$. Protection is mediated by neutralizing antibodies ${ }^{54}$, although the titres produced by L2 vaccination are much lower than for L1 VLP vaccines ${ }^{55}$. However, unlike L1-specific neutralizing antibodies, L2-specific neutralizing antibodies are broadly cross-neutralizing ${ }^{55}$. Indeed, L2 vaccines can provide cross-protection in animal models; vaccination with HPV16 L2 protects against cottontail rabbit papillomavirus (CRPV) and rabbit oral papillomavirus (ROPV) challenge (N. Christensen and R. R., unpublished observations). Therefore, efforts to improve the immunogenicity of L2 and development for clinical testing of L2 vaccines are underway. The ability to produce L2 in Escherichia coli and the potential to use a single antigen suggest that L2 vaccines have potential as a low cost alternative or complement to the L1 VLP vaccines.

\section{How long will protection last?}

It is unclear how long protection from the HPV L1 VLP vaccines will last, but several large studies are ongoing to address this issue. Two intermediate-term studies have been conducted (TABLE 1). At 3.5 years after vaccination with HPV16 L1 VLPs, protection against persistent HPV 16 infection remained at 94\% (95\% CI 88-98) $)^{41}$, compared with $100 \%$ (95\% CI 90-100) at 17.4 months $^{37}$. Notably, all 12 incident cases of HPV16-related highgrade CIN were in the placebo group ${ }^{41}$. A second study showed $94.3 \%$ (95\% CI 63.2-99.9) protection against persistent infection (defined as at least 6 months) at 4.5 years after vaccination ${ }^{40}$. Furthermore, the serum antibody titres seemed stable in both studies, suggesting the possibility of long-term protection. At present, the vaccine is given as a series of three injections. It will be important to examine whether two, rather than three, vaccinations are sufficient to confer protection, and if, or when, a booster immunization is required to maintain immunity. The use of fewer doses would reduce costs. In support of this possibility, patients in clinical trials who received only two doses seemed to be protected ${ }^{41}$. Alternative adjuvants might also be used to extend the duration of protection, or reduce the number of immunizations.

\section{At what age should we vaccinate?}

Vaccination before the initiation of sexual activity is optimal. Although the vaccine is effective in women aged 15-25 (TABLE 1), it could be more problematic to attain comprehensive vaccination in adolescents and adults relative to infants. If the protection provided by VLP vaccination is long in duration and does not compete with other vaccine regimens, then early childhood vaccination might be considered, possibly with a boost later. Importantly, a bridging study in 9-15 year old adolescents versus 16-26 year old young women showed significantly higher immune response to the quadrivalent VLP vaccine in the adolescents ${ }^{56}$, and the FDA has licensed this vaccine for women aged 9-26. Early vaccination might also offer protection in cases of abuse or possible non-sexual transmission. However, vaccination too early and without boosters could lead to break-through infections later in life ${ }^{57}$. 
Sexually active adults should also be considered for a 'catch-up' vaccination. Uninfected women would probably be protected, and there is no evidence that vaccination of those with current or previous HPV infections is harmful. For infected women, the vaccine might prevent the acquisition of other HPV types, prevent or reduce transmission to naïve partners, and/or prevent auto-inoculation. The vaccination of women with genital warts might also reduce the vertical transmission of HPV6 and HPV11, which can cause recurrent respiratory papillomatosis ${ }^{58}$ and airway obstruction in infants.

\section{Other outstanding issues with HPV vaccines}

Do L1 VLP vaccines provide therapeutic benefit? Late gene expression requires the epithelial differentiation of keratinocytes that harbour HPV. Not only are cervical carcinoma cells undifferentiated, the viral DNA is integrated, which could potentially disrupt the $L 1$ gene. Therefore, neither infected basal keratinocytes nor cervical cancer cells express detectable levels of L1, and so are unlikely to be recognized by L1-specific cytotoxic T cells. However, a bystander effect or immune recognition of L1 levels below the level of experimental detection are possible ${ }^{59,60}$. For example, the vaccination of mice

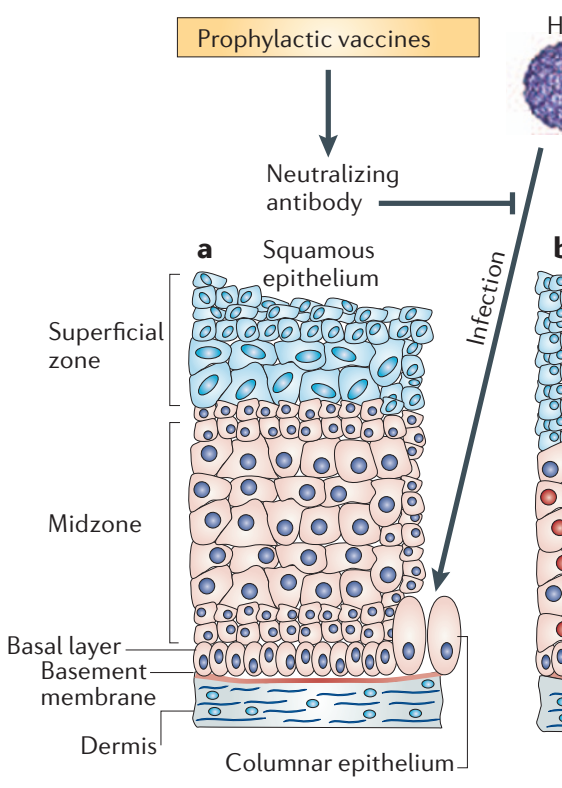

Transformation zone

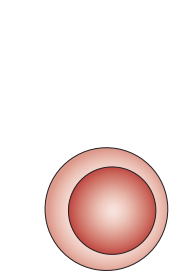

HPVE protein-specific T cells
HPV Pap screening - low sensitivity/high specificity HPV testing - high sensitivity/low specificity
Surgery

Chemotherapy

Radiation
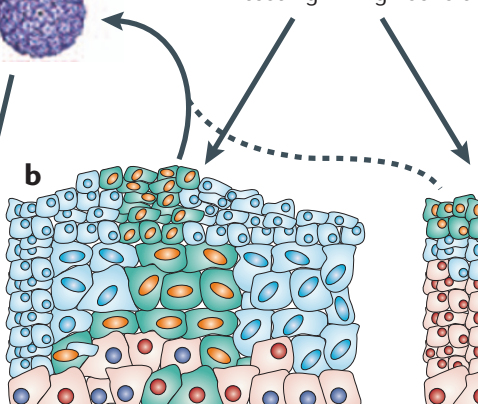

(o

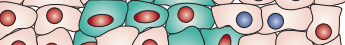

- So 0.0 0.0

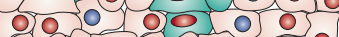
- $000 \% 00000$ o) 0 o o o o 0

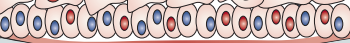
두응 $=0 \div 0$

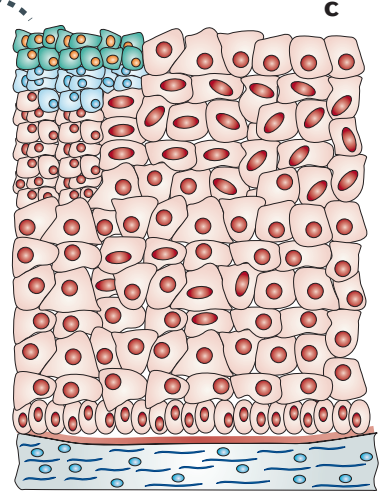

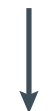

d
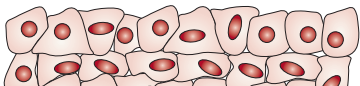
00 o 00

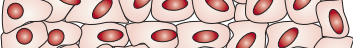
or oloror ô. - 0 0. 0 o o o - O o o jolo

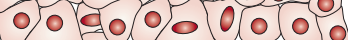
oo 0 os olo - o 0000000 o o o o ol o o

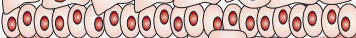

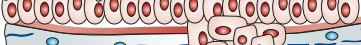
$\frac{0-0}{0-0} 000=0-0$ loge (0) (1)
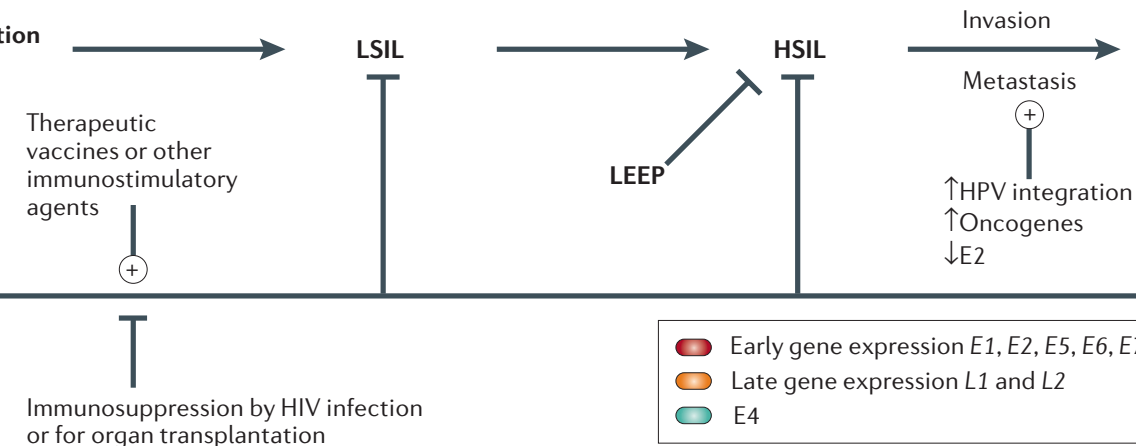

Invasive cancer

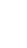




\title{
Box 2 | Screening for cervical HPV infection and related disease
}

\begin{abstract}
Cytology
A Pap smear is a cytological test in which cells from a woman's cervix are collected using a brush, spread on a microscope slide and screened by a pathologist for abnormal cells. Newer liquid-based techniques enable the collection of cells for both microscopic evaluation and human papillomavirus (HPV) DNA detection. Women with abnormal cells are referred for colposcopic evaluation of the cervix, and lesions are confirmed by directed biopsy. The referral of women with high-grade squamous intraepithelial lesion (HSIL) or more severe cytology is highly specific but insensitive, whereas the referral of women with low-grade squamous intraepithelial lesion, atypical squamous cells of unknown significance (LSIL or ASCUS) or more severe results is sensitive but relatively nonspecific. The success of cytological screening programmes in reducing cervical cancer incidence depends on the cumulative sensitivity achieved with repeated lifetime screens and compliance with follow-up examinations. High-risk HPV infection triggers $\mathrm{p} 16^{\mathrm{INK} 4 \mathrm{~A}}$ overexpression, which might be useful in improving cytological screening ${ }^{116}$.
\end{abstract}

\section{'See-and-treat'}

A lower cost, single-visit approach of direct visualization of the cervix after the application of dilute acetic acid and immediate intervention when required. Neither its reliability nor the impact of overtreatment have been firmly established.

\section{Molecular testing}

The US Food and Drug Administration has approved the Hybrid Capture 2 (HC2) test for the detection of high- or low-risk HPV DNA in liquid-based cervical specimens that are obtained for cytological screening ${ }^{117}$. Alternative approaches to HPV DNA detection using PCR and self-collection are also being considered to reduce costs and simplify logistics ${ }^{118}$. Tests for HPV DNA are very sensitive for the detection of HSIL and can be performed in high throughput, but they have lower specificity than cytological screening because HPV DNA testing also detects latent HPV infections and HPVassociated low-grade lesions that ordinarily are not treated because of substantial regression rates. The predictive value of a negative HPV test is very high, so screening intervals might be expanded in women over 30 to further improve cost effectiveness ${ }^{79}$

\section{Adjuvant}

Vaccine components that nonspecifically increase the immune response to the immunogen. Adjuvants are important because they typically increase vaccine efficacy. Examples of adjuvants include alum and $\mathrm{ASO} 4$, a propriety adjuvant comprising alum and the toll-like receptor 2 agonist 3-deacylated monophosphoryl lipid A.

Indirect enzyme-linked immunosorbent assay (ELISA) A quantitative in vitro test for antibody concentration in which the test antigen is adsorbed on a surface and exposed to an antibody specific for the antigen, then an enzyme linked to an anti immunoglobulin specific for the antibody. This is followed by the reaction of the enzyme with a substrate to yield a coloured product that can be quantified.

Immunodominant

An epitope within an antigen that provokes the most intense immune response. with HPV16 VLPs induces effective L1-specific CD8dependent protection from challenge with an HPV16 genome-transformed murine tumour line that does not express levels of L1 protein detectable by western blot or immunofluorescence ${ }^{59}$. Furthermore, patients with genital warts vaccinated with HPV6 L1 VLPs had more frequent clearance than historical controls, but this trial was not placebo controlled ${ }^{61}$. Finally, in women vaccinated with HPV16 L1 VLPs, protection against persistent HPV16 infection was 100\% (95\% CI, 90-100), but $91.2 \%$ (95\% CI, 80-97) when women with pre-existing transient infection were included ${ }^{37}$. The greater efficacy of protection against persistent versus transient HPV infection might be explained by either the immune clearance of some infections or the detection of neutralized virus (as the assay detects viral DNA not viral transcripts). Alternatively, initial infection could be maintained by successive rounds of auto-inoculation that can be interrupted by vaccine-induced neutralizing antibodies. The potential for therapeutic activity of the VLP vaccines against established infection or CIN warrants further study.

Can therapeutic activity be included in preventive $H P V$ vaccines? Given the current prevalence of HPV, and the lack of proven therapeutic efficacy of the L1 VLP vaccines, the effect on cervical cancer rates will be delayed by at least 15 years, although a reduction in the number of surgeries to remove premalignant lesions should be seen sooner. To help currently infected patients and speed up the effect of vaccination on the incidence of cervical cancer, it is important to continue efforts to develop a combination of preventive and therapeutic vaccines.

The lower rate of clearance of HPV-associated lesions in immunodeficient compared with immunocompetent patients indicates that cell-mediated immune responses are important for the control of established HPVassociated disease $\mathrm{e}^{62,63}$. Therefore, it is important that therapeutic vaccines generate HPV-specific cellular immune responses (for reviews see REFS 64,65). As the late proteins L1 and L2 are not detected in cervical cancer or infected basal cells, most therapeutic vaccines target the HPV early proteins such as E6 and E7. Therefore, a combination of preventive and therapeutic vaccines should combine both late and early antigens and induce both neutralizing antibodies and early protein-specific cellular immunity. One attractive approach is chimeric VLPs that contain L1 for prophylaxis and early viral antigens to trigger viral clearance $e^{66-68}$. Another potential preventive and therapeutic vaccine that was safe and immunogenic in patients is TA-CIN, a fusion protein comprising HPV16 L2, E6 and E7 (REF. 69). Although TA-CIN alone did not show significant therapeutic efficacy against anogenital intraepithelial neoplasia, it might be more effective if formulated with the appropriate adjuvant ${ }^{70}$.

Will vaccination change the HPV types that cause cervical cancer? One theoretical issue with type-restricted protection against HPV is that types other than those included in the vaccine might proliferate to fill the ecological niche left by the types against which the vaccine is effective. Two HPV types can replicate in the same cell ${ }^{71}$, but recombination between HPV genotypes is lacking in isolates, which suggests that natural co-infection of the same cell is uncommon. Furthermore, epidemiological studies indicate that competition between types for infection of the host is not significant ${ }^{7,72}$.

Seroepidemiological evidence exists for protection against HPV16-related cervical carcinogenesis by infection with the low-risk type HPV6 (REF. 73). However, this probably reflects cross-protection through cellular immunity rather than competition for replication in a particular niche. Indeed, over 4 years of follow-up an increase in disease relating to types other than those in the VLP vaccines was not observed. Koutsky et al. reported 22 cases of incident CIN related to types other than HPV16 in both the placebo and HPV16 L1 VLP groups of their trial ${ }^{37}$. This is also borne out over 3.5 years ${ }^{41}$ (FIG. 3a). Similarly, in the study by Harper et al..$^{40}$ similar numbers of infections with types other than those targeted by vaccination were present in both the placebo and vaccine groups (FIC. 3b). These studies indicate that in the short term there is no expansion of other HPV types into the large potential niche created after vaccination against the two most common cancer-causing types. In the unlikely event that this does occur over time, additional VLP types, or perhaps an L2 cross-protective antigen, could be included in the vaccine. 


\begin{tabular}{|c|c|c|c|c|c|c|c|c|c|c|}
\hline $\begin{array}{l}\text { Sponsor/ } \\
\text { study }\end{array}$ & $\begin{array}{l}\text { VLP } \\
\text { types }\end{array}$ & $\begin{array}{l}\text { Antigen } \\
\text { Source }\end{array}$ & Adjuvant & $\begin{array}{l}\text { Timing of } \\
\text { vaccination } \\
\text { (months) }\end{array}$ & $\begin{array}{l}\text { Patients } \\
\text { per group } \\
\text { (placebo/ } \\
\text { active) }\end{array}$ & Age & $\begin{array}{l}\text { Duration } \\
\text { of study } \\
\text { (months) }\end{array}$ & $\begin{array}{l}\text { Protection } \\
\text { against } \\
\text { persistent } \\
\text { infection by } \\
\text { homologous } \\
\text { types } \\
(\%(95 \% \mathrm{CI}))\end{array}$ & $\begin{array}{l}\text { Protection } \\
\text { against } \\
\text { >ASCUS } \\
\text { homologous } \\
\text { types } \\
(\%(95 \% \mathrm{CI}))\end{array}$ & $\begin{array}{l}\text { Protection } \\
\text { against } \\
\text { >ASCUS } \\
\text { by any HPV } \\
\text { type } \\
(\%(95 \% \mathrm{Cl}))\end{array}$ \\
\hline Merck $^{41}$ & 16 & Yeast & Alum & $0,2,6$ & $750 / 755$ & $16-23$ & 36 & $100 \%(85-100)$ & $100 \%(84-100]$ & $31 \%(0-57)$ \\
\hline Merck $^{39}$ & $\begin{array}{l}6,11 \\
16,18\end{array}$ & Yeast & Alum & $0,2,6$ & $275 / 277$ & $16-23$ & 35 & $89 \%(70-97)$ & $100 \%(16-100)$ & NR \\
\hline $\mathrm{GSK}^{38}$ & 16,18 & Baculovirus & ASO4 & $0,1,6$ & $366 / 355$ & $15-25$ & 27 & $74 \%(50-86)$ & $93 \%(70-98)^{\star}$ & NR \\
\hline $\mathrm{GSK}^{40}$ & 16,18 & Baculovirus & ASO4 & $0,1,6$ & $383 / 393$ & $15-25$ & 48 & $94 \%(63-100)$ & $93 \%(71-99)$ & $45 \%(17-63)$ \\
\hline
\end{tabular}

*Includes atypical squamous cells of unknown significance (ASCUS). ${ }^{\ddagger}$ Homologous types are the same human papillomavirus (HPV) types as were used to derive the virus-like particle (VLP) vaccine. ${ }^{\S}>$ ASCUS is a diagnosis greater than ASCUS; CI, confidence interval; GSK, GlaxoSmithKline; NR, not reported.

\section{Conformational \\ When an epitope requires a specific spatial arrangement for recognition. \\ Specificity \\ The probability that the result of a test is negative given that the individual tested does not have the disease. \\ Sensitivity \\ The probability of a positive test result given that the individual tested actually has the disease. \\ Squamous epithelium A sheet of cells covering or lining an external surface and consisting of more than one cell layer, the most superficial of which is composed of flat, scale-like cells.}

Sterilizing immunity An immune response that completely eliminates an infection

\section{Exudation}

The slow escape of a fluid from damaged blood vessels.

\section{Multivalent}

Including more than one HPV genotype.

\section{Neutralization assay}

A measurement of the efficacy of antibody-mediated inactivation of an infectious agent.

\section{Auto-inoculation}

The spread of infection from one part to other parts of the same body.
Will HPV evolve to escape neutralization? HPV uses the replication machinery of the host cell to propagate its genome, which results in very low error rates compared with viruses like human immunodeficiency virus (HIV) that use their own error-prone machinery to copy their genomes $^{74}$. Therefore, HPV sequences are very stable over time. Nonetheless, within HPV genotypes there are many variants with about $2 \%$ sequence divergence. Many of these changes are in L1 neutralizing epitopes, which suggests selection to escape neutralization ${ }^{75,76}$. Simlarly, these epitopes are highly divergent between genotypes, which is consistent with successful escape from neutralizing antibodies resulting from infections by other HPV genotypes. Evidence indicates that variants within an HPV type are effectively cross-neutralized by antisera to L1 VLPs derived from another variant in the same HPV genotype ${ }^{46,77}$. Given this cross-neutralization of variants and the slow rate of HPV sequence change, immune escape is unlikely to be a significant issue.

How will the vaccine influence screening programmes? Cytological screening (BOX 2) and intervention has reduced the incidence of cervical cancer in the United States by an estimated $80 \%$. However, this programme is costly and screening is inconvenient. Unfortunately, current vaccine formulations do not protect against all oncogenic HPV genotypes or treat existing disease, and therefore screening programmes must remain in place. The cost of cervical cancer screening is sensitive to the degree of aggressive follow-up and management of low-grade lesions, which are likely to regress without intervention. Because these low-grade lesions are less likely to be associated with HPV16 or 18 (REF. 3), costeffectiveness for a combined vaccination and screening programme will require less aggressive management of minor abnormalities than is currently standard in many developed countries. Modelling studies have suggested that the most cost-effective approach to using a vaccine targeting HPV16 and 18 is to combine vaccination at age 12 with triennial cytological screening beginning at age 25 (REF. 78). These recommendations are most feasible using screening algorithms that combine cervical cytology and high-risk HPV DNA testing. HPV testing is highly reproducible, and very sensitive for the detection of HPV-related lesions ${ }^{79}$. Furthermore, a negative HPV test provides more certainty of the absence of HPVrelated lesions than a negative cytological screen, and might permit the safe expansion of screening intervals in vaccinated women. More broadly protective multivalent L1 VLP or L2-based vaccines might further reduce the need for screening.

How can a vaccine be introduced in low resource areas? Cervical cancer takes a disproportionate toll on those who lack access to screening, and it is predicted that the L1 VLP vaccine will cost several hundred US dollars per person. In low-resource settings, the relative benefits of cervical cancer screening, especially if the cost of screening was lowered, versus HPV vaccination might have to be considered. Cooperation between governmental and international organizations such as the World Health Organization (WHO) and The Global Alliance for Vaccines and Immunization (GAVI), the pharmaceutical industry and charities will be crucial to disseminate the current VLP vaccines as broadly as possible. Local manufacture of vaccines might facilitate global distribution, but it is necessary to ensure that the safety and efficacy of locally produced HPV vaccines matches or exceeds those currently available.

Although current L1 VLP vaccines are produced in insect cells or yeast, cheaper production in E. coli is a possibility. The expression of L1 in E. coli produces capsomers that can self-assemble in vitro ${ }^{80-82}$, and vaccination with such capsomers induces neutralizing antibodies $^{81,83}$ and protects dogs from experimental canine oral papillomavirus challenge ${ }^{84}$. Also, the current L1 VLP vaccines require refrigeration, which might be problematic in remote and low-resource areas. One potential advantage of the L1 capsomer vaccine is its stability at ambient temperature.

The requirement for needles to inject the current VLP vaccines also complicates delivery in low-resource areas. Many possible needle-free alternatives are currently under consideration, including nasal inhalation and transdermal vaccination ${ }^{85,86}$. Alternatively, 
the inclusion of L1 in other vaccines, specifically the typhoid, tuberculosis or measles vaccines, might represent a cost-effective and practical alternative that could also provide immunity to $\mathrm{HPV}^{87-90}$. The use of live

\begin{abstract}
Respiratory papillomatosis HPV-caused warty growths in the upper airway that can produce significant airway obstruction or voice change.

\section{Late gene}

Early or late genes and early or late proteins are two

classes of genes or proteins that are produced by different viral expression programmes: 'early' proteins regulate viral DNA replication (E1 and E2), RNA transcription (E2), cell transformation (E5, E6 and E7) and cytoskeletal morphogenesis (E4), whereas 'late' proteins (L1 and L2) represent the structural components of the viral capsid. The early and late expression programmes are tightly regulated and linked to the differentiation status of the infected squamous epithelial cells

Cytotoxic T cell A thymocyte that functions in cell-mediated immunity by destroying a cell that displays a specific antigen on its surface.
\end{abstract}

Bystander effect

Secondary effects on adjacent cells and tissues triggered by immune recognition of a primary target.

Seroepidemiology The study of the patterns, causes and control of disease in groups of people by measurements of serum components

\section{Capsomers}

Repetitive structural subunits that form the capsid of a virus.

\section{Herd immunity}

The resistance of a population to an infectious agent due to the immunity of a high proportion of the population.

\section{Seroconvert}

When a patient converts from having a negative to a positive result in a serological assay.

$\mathrm{CD}^{+}{ }^{+} \mathrm{T}$ cell

Helps stimulate immune system reactions but does not usually directly kill target cells.
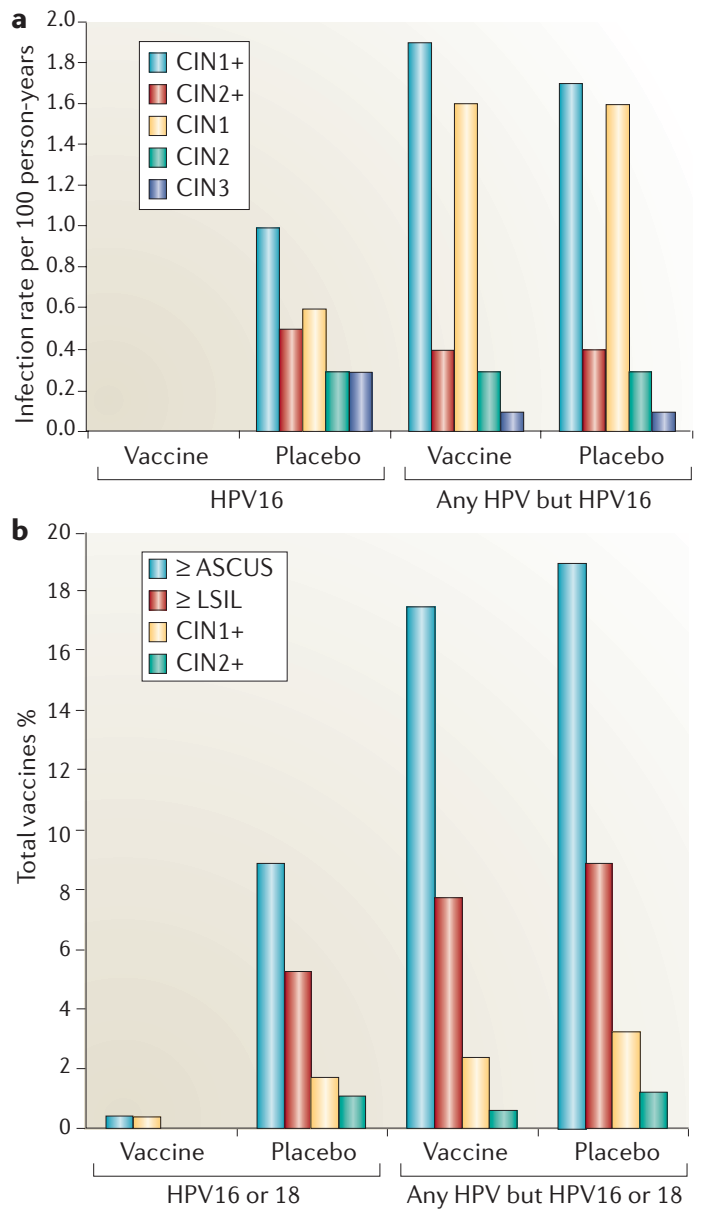

Figure 3 | Protection by human papillomavirus L1 viruslike particle (HPV L1 VLP) vaccination is type restricted. a|A plot of data described in Mao et al. for women vaccinated with HPV16 L1 VLPs (vaccine) or placebo ${ }^{41}$. Bars show the infection rate per 100 person-years for women in each group with cervical intraepithelial neoplasia 1 or worse (CIN1+), or CIN2 or worse (CIN2+), or CIN3. These lesions are presented as either HPV16 DNA positive, or DNA positive for any genotype other than HPV16. b |A plot of data described in Harper et al. showing that vaccination with HPV16 and HPV18 L1 VLPs in ASO4 provided complete protection over 4 years against HPV16 or HPV18related CIN1 or greater ${ }^{40}$. Bars show the percentage of total women in each group with atypical squamous cells of unknown significance (ASCUS) or worse ( $\geq$ ASCUS), a lowgrade squamous intraepithelial lesion or worse ( $\geq$ LSIL), $\mathrm{CIN} 1$ or worse $(\mathrm{CIN} 1+)$, or $\mathrm{CIN} 2$ or worse $(\mathrm{CIN} 2+)$. These lesions are presented as either HPV16 or HPV18 DNA positive, or DNA positive for any type other than HPV16 or HPV18. However, significant protection against $\mathrm{CIN}$ related to any other type (en masse) was not observed. Note that the study found $94 \%$ (95\% Cl 63.9-99.9) protection against HPV45 infection, and 54\% (95\% Cl 11.5-77.7) HPV31 infection, showing that the type restriction of protection is not absolute. vectors for the delivery of L1 VLPs is attractive in remote and low-resource areas as immunity could be spread, but safety remains an issue with such vectors.

Should males be vaccinated? Studies of HPV in men have lagged behind those in women because men do not face cervical cancer. Is the cost/benefit ratio sufficient to warrant the vaccination of boys or men? Data on which to base this decision are not yet available. The inclusion of VLPs for low-risk types that protect against benign genital warts could influence this equation by reducing physician visits for ablative or immunostimulatory therapies, but might come at the cost of protecting against fewer high-risk types. Studies in men are also important to address the issue of protection against HPV-related cancers at other sites, as high-risk HPV does cause a significant fraction of anal cancers (90\%), penile cancers (40\%) and oropharyngeal $(12 \%)$ and oral (3\%) cancers $^{8,91}$. The vaccination of men raises the possibility of more rapid and effective protection of women through herd immunity ${ }^{92}$. However, although modelling suggests that the influence of herd immunity through the vaccination of males is likely to be beneficial, it will have only a modest effect on cervical cancer rates compared with the broad vaccination of women ${ }^{57,93}$. Nevertheless, the vaccination of males must be seriously considered to prevent HPV-related cancers at non-cervical sites.

How will immunosuppressed patients respond? The frequency of viral clearance and lesion regression is significantly lower in immunosuppressed patients, such as organ transplant recipients and HIV co-infected patients ${ }^{62,63}$. Organ transplant recipients and HIVinfected patients have more severe and recalcitrant disease, higher viral loads, infections with unusual HPV genotypes and greater propensity for HPVrelated malignancies, especially cervical cancer (an eightfold increased risk in HIV-infected women) and anal cancer (a 42-fold increased risk in HIV-infected men $)^{94,95}$. Therefore, an HPV vaccine would be very important in these patients. However, it is unclear how HIV infected and immunosuppressed patients will respond to the HPV VLP vaccines and whether additional boosts would be helpful. Most HIV-infected patients do seroconvert after vaccination against hepatitis $\mathrm{B}$, although the response strongly correlates with CD4 ${ }^{+}$T-cell counts ${ }^{96}$. However, CD4-deficient mice can generate a limited response to HPV VLP vaccination ${ }^{60}$. These findings offer hope that a significant proportion of immunocompromised patients will respond to the HPV L1 VLP vaccines, possibly with additional boosts, more potent adjuvants and higher doses. However, immunodeficient patients also suffer from infections and cancers resulting from various HPV types that do not normally cause disease in the immunocompetent. These types are not covered by the current HPV VLP vaccines, and perhaps an L2 vaccine might be useful for this reason. Finally, HPV is a more common infection than HIV, and therefore most HIV-infected patients are likely to have already been infected with HPV too. 
Should the HPV vaccine be mandatory? The HPV vaccine raises a number of ethical issues that might affect its use ${ }^{97,98}$. Vaccination is not without risk, and evidence suggests that other measures, including condoms, abstinence and male circumcision, are quite effective at limiting the spread of HPV disease $e^{99,100}$. Although concern that HPV vaccination will promote risky sexual behaviour has been expressed, fear of HIV probably dominates ${ }^{101}$. Indeed, hepatitis $\mathrm{B}$ can be spread through sexual contact, and we are unaware of evidence that the global introduction of the hepatitis B virus vaccine has promoted risky sexual behaviour. Effective education programmes and mandatory vaccination will probably provide the greatest and fastest reduction in the incidence of cervical cancer ${ }^{102}$.

\section{Future directions}

Mathematical modelling of the effect of HPV L1 VLP vaccine introduction on cervical cancer rates is ongoing ${ }^{57,103,104}$, and the accuracy of the predictions will improve as we know more of the variables, such as long-term efficacy and the breadth of coverage. Although the HPV vaccine has the potential to be a dramatic public-health success, this depends on societal acceptance through education ${ }^{102}$ and logistic factors that influence the coverage of immunization. Other factors include the number of types that are incorporated in the multivalent VLP vaccines, the degree of cross-protection, and who is vaccinated (that is, which gender and ages and how effective the vaccine is in immunosuppressed patients). It is probable that the breadth of coverage will be further extended with increasing valency, or possibly by the inclusion of $\mathrm{L} 2$.

HPV infection caused $5.2 \%$ of all cancers worldwide in 2002 , about 561,200 cases $^{8}$. Therefore, HPV is one of the most important agents of cancer causation, and the new VLP vaccines provide the opportunity to reduce cancer rates in a couple of decades. If this opportunity is to be fully realized, issues relating to global vaccine delivery must be addressed. For example, despite the availability of an effective vaccine against hepatitis B for two decades, in 2002340,000 cases of liver cancer were attributed globally to hepatitis B infection ${ }^{8}$. Over $90 \%$ of these cases occurred in developing countries, reflecting a disparity in vaccination programmes. Therefore, efforts to reduce the cost of HPV vaccination and facilitate the delivery of the vaccine through governmental, private and charitable support, local vaccine manufacture and the development of needlefree, heat-stable, single-dose formulations must continue.

Finally, high-risk HPV contributes to a significant fraction of head and neck, anal, penile, vulvar and vaginal cancers. Although these cancers are less common than cervical cancer, it will be important to determine whether the benefits of the HPV preventive vaccine extend beyond cervical cancer.
1. Bosch, F. X., Lorincz, A., Munoz, N., Meijer, C. J. \& Shah, K. V. The causal relation between human papillomavirus and cervical cancer. J. Clin. Pathol. 55, 244-265 (2002)

2. zur Hausen, H. Papillomaviruses and cancer: from basic studies to clinical application. Nature Rev. Cancer 2, 342-350 (2002).

3. Clifford, G. M. et al. Worldwide distribution of human papillomavirus types in cytologically normal women in the International Agency for Research on Cancer HPV prevalence surveys: a pooled analysis. Lancet 366 . 991-998 (2005)

4. de Villiers, E. M., Fauquet, C., Broker, T. R., Bernard, H. U. \& zur Hausen, H. Classification of papillomaviruses. Virology 324, 17-27 (2004).

5. Kurman, R. J., Malkasian, G. D. Jr, Sedlis, A. \& Solomon, D. From Papanicolaou to Bethesda: the rationale for a new cervical cytologic classification. Obstet. Gynecol. 77, 779-782 (1991).

6. Ho, G. Y., Bierman, R., Beardsley, L., Chang, C. J. \& Burk, R. D. Natural history of cervicovaginal papillomavirus infection in young women. N. Engl. J. Med. 338, 423-428 (1998).

7. Trimble, C. L. et al. Spontaneous regression of high-grade cervical dysplasia: effects of human papillomavirus type and HLA phenotype. Clin. Cancer Res. 11, 4717-4723 (2005)

8. Parkin, D. M. The global health burden of infection-associated cancers in the year 2002. Int. J. Cancer 118, 3030-3044 (2006).

9. US Food and Drug Administration. Product approval information - licensing action. US Food and Drug Administration [online], http://www.fda.gov/CBER/ products/hpvmer060806.htm (2006).

10. Koller, L. D. \& Olson, C. Attempted transmission of warts from man, cattle, and horses and of deer fibroma, to selected hosts. J. Invest. Dermatol. 58, 366-368 (1972)

11. Shope, R. E. Immunization of rabbits to infectious papillomatosis. J. Exp. Med. 65, 219-231 (1937).

12. Dvoretzky, I., Shober, R., Chattopadhyay, S. K. \& Lowy, D. R. A quantitative in vitro focus assay for bovine papilloma virus. Virology 103, 369-375 (1980).

13. Christensen, N. D. \& Kreider, J. W. Antibody-mediated neutralization in vivo of infectious papillomaviruses. J. Virol. 64, 3151-3156 (1990)
14. Bonnez, W., Rose, R. C. \& Reichman, R. C. Antibodymediated neutralization of human papillomavirus type 11 (HPV- 11) infection in the nude mouse: detection of HPV-11 mRNAs. J. Infect. Dis. 165, 376-380 (1992).

15. Rose, R. C., Bonnez, W., Reichman, R. C. \& Garcea, R. L. Expression of human papillomavirus type $11 \mathrm{~L} 1$ protein in insect cells: in vivo and in vitro assembly of viruslike particles. J. Virol. 67, 1936-1944 (1993).

16. Bell, J. A. et al. A formalin-inactivated vaccine protects against mucosal papillomavirus infection: a canine model. Pathobiology 62, 194-198 (1994)

17. Jarrett, W. F. et al. Studies on vaccination against papillomaviruses: a comparison of purified virus, tumour extract and transformed cells in prophylactic vaccination. Vet. Rec. 126, 449-452 (1990).

18. Breitburd, F. et al. Immunization with viruslike particles from cottontail rabbit papillomavirus (CRPV) can protect against experimental CRPV infection. J. Virol. 69, 3959-3963 (1995).

Shows that the passive transfer of immune sera from a VLP-vaccinated animal protects a naïve animal from experimental papillomavirus challenge. The study also shows the conformational nature of protective epitopes, and that L2 is not required in VLPs for protection.

19. Lin, Y. L., Borenstein, L. A., Ahmed, R. \& Wettstein F. O. Cottontail rabbit papillomavirus L1 protein-based vaccines: protection is achieved only with a full-length, nondenatured product. J. Virol. 67, 4154-4162 (1993)

20. Hagensee, M. E., Yaegashi, N. \& Galloway, D. A Self-assembly of human papillomavirus type 1 capsids by expression of the L1 protein alone or by coexpression of the L1 and L2 capsid proteins. J. Virol. 67, 315-322 (1993)

21. Heino, P., Dillner, J. \& Schwartz, S. Human papillomavirus type 16 capsid proteins produced from recombinant Semliki Forest virus assemble into virus-like particles. Virology 214, 349-359 (1995).

22. Kirnbauer, R., Booy, F., Cheng, N., Lowy, D. R. \& Schiller, J. T. Papillomavirus L1 major capsid protein self-assembles into virus-like particles that are highly immunogenic. Proc. Natl Acad. Sci. USA 89 12180-12184 (1992)

23 Rose, R. C., Reichman, R. C. \& Bonnez, W. Human papillomavirus (HPV) type 11 recombinant virus-like particles induce the formation of neutralizing antibodies and detect HPV-specific antibodies in human sera. J. Gen. Virol. 75, 2075-2079 (1994).

24. Sasagawa, T. et al. Synthesis and assembly of virus like particles of human papillomaviruses type 6 and type 16 in fission yeast Schizosaccharomyces pombe. Virology 206, 126-135 (1995).

25. Nardelli-Haefliger, D. et al. Human papillomavirus type 16 virus-like particles expressed in attenuated Salmonella typhimurium elicit mucosal and systemic neutralizing antibodies in mice. Infect. Immun. 65 , 3328-3336 (1997).

References 20-25 show the production of HPV VLPs by the recombinant production of L1 protein in various expression systems.

26. Ghim, S. J., Jenson, A. B. \& Schlegel, R. HPV-1 L protein expressed in cos cells displays conformational epitopes found on intact virions. Virology 190, 548-552 (1992)

27. Suzich, J. A et al. Systemic immunization with papillomavirus L1 protein completely prevents the development of viral mucosal papillomas. Proc. Natl Acad. Sci. USA 92, 11553-11557 (1995). Shows that the passive transfer of immune sera from a VLP-vaccinated animal protects a naïve dog from experimental papillomavirus challenge.

28. Kirnbauer, R. et al. Virus-like particles of bovine papillomavirus type 4 in prophylactic and therapeutic immunization. Virology 219, 37-44 (1996).

29. Christensen, N. D. Reed, C. A. Cladel, N. M., Han, R. \& Kreider, J. W. Immunization with viruslike particles induces long-term protection of rabbits against challenge with cottontail rabbit papillomavirus. J. Virol. 70, 960-965 (1996).

References 27-29 show that vaccination with VLPs protects animals from experimental challenge with homologous-type animal papillomavirus.

30. Nardelli-Haefliger, D. et al. Mucosal but not parenteral immunization with purified human papillomavirus type 16 virus-like particles induces neutralizing titers of antibodies throughout the estrous cycle of mice. J. Virol. 73, 9609-9613 (1999).

31. Nardelli-Haefliger, D. et al. Specific antibody levels at the cervix during the menstrual cycle of women vaccinated with human papillomavirus 16 virus-like particles. J. Natl Cancer Inst. 95, 1128-1137 (2003). 
32. Harro, C. D. et al. Safety and immunogenicity trial in adult volunteers of a human papillomavirus $16 \mathrm{~L}$ virus-like particle vaccine. J. Natl Cancer Inst. 93, 284-292 (2001)

33. Evans, T. G. et al. A Phase 1 study of a recombinant viruslike particle vaccine against human papillomavirus type 11 in healthy adult volunteers. J. Infect. Dis. 183, 1485-1493 (2001).

34. Ault, K. A. et al. A phase I study to evaluate a human papillomavirus (HPV) type 18 L1 VLP vaccine. Vaccine 22, 3004-3007 (2004).

35. Brown, D. R. et al. Early assessment of the efficacy of a human papillomavirus type $16 \mathrm{~L} 1$ virus-like particle vaccine. Vaccine 22, 2936-2942 (2004).

36. Fife, K. H. et al. Dose-ranging studies of the safety and immunogenicity of human papillomavirus Type 11 and Type 16 virus-like particle candidate vaccines in young healthy women. Vaccine 22, 2943-2952 (2004)

37. Koutsky, L. A. et al. A controlled trial of a human papillomavirus type 16 vaccine. N. Engl. J. Med. 347, 1645-1651 (2002).

A landmark trial showing that vaccination with HPV1 6 L1 VLPs protects against the natural acquisition of persistent HPV16 infection and HPV16-associated CIN.

38. Harper, D. M. et al. Efficacy of a bivalent L1 virus-like particle vaccine in prevention of infection with human papillomavirus types 16 and 18 in young women: a randomised controlled trial. Lancet 364, 1757-1765 (2004).

39. Villa, L. L. et al. Prophylactic quadrivalent human papillomavirus (types 6, 11, 16, and 18) L1 virus-like particle vaccine in young women: a randomised double-blind placebo-controlled multicentre phase II efficacy trial. Lancet Oncol. 6, 271-278 (2005). A trial that shows the efficacy of a multivalent VLP vaccine comprising L1 VLPs of HPV6, 11, 16 and 18 for protection against HPV 16 and 18-related $\mathrm{CIN}$ and protection against external genital warts.

40. Harper, D. M. et al. Sustained efficacy up to 4.5 years of a bivalent L1 virus-like particle vaccine against human papillomavirus types 16 and 18: follow-up from a randomised control trial. Lancet 367 1247-1255 (2006).

A trial that shows cross-protection against homologous type HPV 16 and 18-related SIL, and SIL associated with very closely related HPV types (HPV31 and 45) after vaccination with HPV16 and HPV 18 L1 VLPs.

41. Mao, C. et al. Efficacy of human papillomavirus-16 vaccine to prevent cervical intraepithelial neoplasia: a randomized controlled trial. Obstet. Gynecol. 107, 18-27 (2006)

42. Robbins, J. B., Schneerson, R. \& Szu, S. C. Perspective: hypothesis: serum IgG antibody is sufficient to confer protection against infectious diseases by inactivating the inoculum. J. Infect. Dis. 171, 1387-1398 (1995)

43. Roden, R. B., Kirnbauer, R., Jenson, A. B., Lowy, D. R. $\&$ Schiller, J. T. Interaction of papillomaviruses with the cell surface. J. Virol. 68, 7260-7266 (1994).

44. Roden, R. B. et al. Neutralization of bovine papillomavirus by antibodies to L1 and L2 capsid proteins. J. Virol. 68, 7570-7574 (1994).

45. Chipperfield, E. J. \& Evans, B. A. Effect of local infection and oral contraception on immunoglobulin levels in cervical mucus. Infect. Immun. 11, 215-221 (1975).

46. Roden, R. B. et al. In vitro generation and type-specific neutralization of a human papillomavirus type 16 virion pseudotype. J. Virol. 70, 5875-5883 (1996).

47. Munoz, N. et al. Against which human papillomavirus types shall we vaccinate and screen? The internationa perspective. Int. J. Cancer 111, 278-285 (2004).

48. Christensen, N. D. et al. Human papillomavirus types 6 and 11 have antigenically distinct strongly immunogenic conformationally dependent neutralizing epitopes. Virology 205, 329-335 (1994)

49. Roden, R. B. et al. Assessment of the serological relatedness of genital human papillomaviruses by hemagglutination inhibition. J. Virol. 70, 3298-3301 (1996).

50. White, W. I. et al. In vitro infection and type-restricted antibody-mediated neutralization of authentic human papillomavirus type 16. J. Virol. 72, 959-964 (1998).

51. Christensen, N. D., Kreider, J. W., Kan, N. C. \& DiAngelo, S. L. The open reading frame $L 2$ of cottontail rabbit papillomavirus contains antibodyinducing neutralizing epitopes. Virology 181 , 572-579 (1991)
52. Campo, M. S. et al. Prophylactic and therapeutic vaccination against a mucosal papillomavirus. J. Gen. Virol. 74, 945-53 (1993)

53. Lin, Y. L., Borenstein, L. A., Selvakumar, R., Ahmed, R. $\&$ Wettstein, F. O. Effective vaccination against papilloma development by immunization with $\mathrm{L} 1$ or $\mathrm{L} 2$ structural protein of cottontail rabbit papillomavirus. Virology 187, 612-619 (1992)

54. Embers, M. E., Budgeon, L. R., Pickel, M. \& Christensen, N. D. Protective immunity to rabbit oral and cutaneous papillomaviruses by immunization with short peptides of 12, the minor capsid protein. J. Virol. 76, 9798-9805 (2002).

References 51-54 show that vaccination with L2 and its peptides protects animals from experimental papillomavirus infection.

55. Roden, R. B. et al. Minor capsid protein of human genital papillomaviruses contains subdominant, cross-neutralizing epitopes. Virology 270, 254-257 (2000).

56. US Food and Drug Administration. CBER-Quadrivalent Human Papillomavirus (Types 6, 11, 16, 18) Recombinant Vaccine, GARDASIL Labeling. US Food and Drug Administration [online], http://www.fda.gov/ cber/label/hpvmer060806LB.htm (2006).

57. Barnabas, R. V. et al. Epidemiology of HPV 16 and cervical cancer in Finland and the potential impact of vaccination: mathematical modelling analyses. PLoS Med. 3, e138 (2006).

58. Kashima, H. K. Mounts, P. \& Shah, K. Recurrent respiratory papillomatosis. Obstet. Gynecol. Clin. North Am. 23, 699-706 (1996)

59. De Bruijn, M. L. et al. L1-specific protection from tumor challenge elicited by HPV 16 virus- like particles. Virology 250, 371-376 (1998)

60. Yang, R. et al. Papillomavirus capsid mutation to escape dendritic cell-dependent innate immunity in cervical cancer. J. Virol. 79, 6741-6750 (2005)

61. Zhang, L. F. et al. HPV6b virus like particles are potent mmunogens without adjuvant in man. Vaccine 18 1051-1058 (2000)

62. Koshiol, J. E. et al. Time to clearance of human papillomavirus infection by type and human immunodeficiency virus serostatus. Int. J. Cancer 119 , 1623-1629 (2006)

63. Palefsky, J. Human papillomavirus-associated malignancies in HIV-positive men and women. Curr. Opin. Oncol. 7, 437-441 (1995).

64. Berry, J. M. \& Palefsky, J. M. A review of human papillomavirus vaccines: from basic science to clinical trials. Front. Biosci. 8, s333-s345 (2003).

65. Pardoll, D. M. Spinning molecular immunology into successful immunotherapy. Nature Rev. Immunol. 2, 227-238 (2002)

66. Muller, M. et al. Chimeric papillomavirus-like particles. Virology 234, 93-111 (1997).

67. Greenstone, H. L. et al. Chimeric papillomavirus viruslike particles elicit antitumor immunity against the E7 oncoprotein in an HPV16 tumor model. Proc. Nat Acad. Sci. USA 95, 1800-1805 (1998).

68. Freyschmidt, E. J., Alonso, A., Hartmann, G. \& Gissmann, L. Activation of dendritic cells and induction of T cell responses by HPV 16 L1/E7 chimeric viruslike particles are enhanced by $\mathrm{CpG}$ ODN or sorbitol. Antivir. Ther 9, 479-489 (2004).

69. de Jong, A. et al. Enhancement of human papillomavirus (HPV) type 16 E6 and E7-specific T-cell immunity in healthy volunteers through vaccination with TA-CIN, an HPV16 L2E7E6 fusion protein vaccine. Vaccine 20, 3456-3464 (2002).

70. Smyth, L. J. et al. Immunological responses in women with human papillomavirus type 16 (HPV-16)associated anogenital intraepithelial neoplasia induced by heterologous prime-boost HPV-16 oncogene vaccination. Clin. Cancer Res. 10, 2954-2961 (2004)

71. McLaughlin-Drubin, M. E. \& Meyers, C. Evidence for the coexistence of two genital HPV types within the same host cell in vitro. Virology 321, 173-180 (2004)

72. Liaw, K. L. et al. A prospective study of human papillomavirus (HPV) type 16 DNA detection by polymerase chain reaction and its association with acquisition and persistence of other HPV types. J. Infect. Dis. 183, 8-15 (2001).

73. Silins, I. et al. Serological evidence for protection by human papillomavirus (HPV) type 6 infection against HPV type 16 cervical carcinogenesis. J. Gen. Virol. 80, 2931-2936 (1999).

74. Chow, L. T. \& Broker, T. R. Papillomavirus DNA replication. Intervirology 37, 150-158 (1994).
75. Roden, R. B. et al. Characterization of a human papillomavirus type 16 variant-dependent neutralizing epitope. J. Virol. 71, 6247-6252 (1997).

76. White, W. I. et al. Characterization of a major neutralizing epitope on human papillomavirus type 16 L1. J. Virol. 73, 4882-4889 (1999).

77. Pastrana, D. V., Vass, W. C., Lowy, D. R. \& Schiller, J. T. NHPV 16 VLP vaccine induces human antibodies that neutralize divergent variants of HPV16. Virology 279 , 361-369. (2001)

78. Goldie, S. J. et al. Projected clinical benefits and cost-effectiveness of a human papillomavirus $16 / 18$ vaccine. J. Natl Cancer Inst. 96, 604-615 (2004).

79. Schiffman, M. \& Castle, P. E. The promise of global cervical-cancer prevention. N. Engl J. Med. 353, 2101-214 (2005).

80. Li, M. et al. Expression of the human papillomavirus type $11 \mathrm{~L} 1$ capsid protein in Escherichia coli: characterization of protein domains involved in DNA binding and capsid assembly. J. Virol. 71 , 2988-2995 (1997).

81. Rose, R. C. et al. Human papillomavirus type 11 recombinant L1 capsomeres induce virus- neutralizing antibodies. J. Virol. 72, 6151-6154 (1998).

82. Chen, X. S., Garcea, R. L., Goldberg, I., Casini, G. \& Harrison, S. C. Structure of small virus-like particles assembled from the L1 protein of human papillomavirus 16. Mol. Cell. 5, 557-567 (2000).

83. Fligge, C., Giroglou, T., Streeck, R. E. \& Sapp, M. Induction of type-specific neutralizing antibodies by capsomeres of human papillomavirus type 33 . Virology 283, 353-357 (2001).

84. Yuan, H. et al. Immunization with a pentameric L1 fusion protein protects against papillomavirus infection. J. Virol. 75, 7848-7853 (2001)

85. Nardelli-Haefliger, D. et al. Immune responses induced by lower airway mucosal immunisation with a human papillomavirus type 16 virus-like particle vaccine. Vaccine 23, 3634-3641 (2005).

86. Rechtsteiner, G., Warger, T., Osterloh, P., Schild, H. \& Radsak, M. P. Cutting edge: priming of CTL by transcutaneous peptide immunization with imiquimod J. Immunol. 174, 2476-2480 (2005)

87 Govan, V. A., Christensen, N. D., Berkower, C. Jacobs, W. R., Jr. \& Williamson, A. L. Immunisation with recombinant BCG expressing the cottontail rabbit papillomavirus (CRPV) L1 gene provides protection from CRPV challenge. Vaccine 24, 2087-2093 (2006).

88. Reuter, J. D. et al. Intranasal vaccination with recombinant vesicular stomatitis virus expressing cottontail rabbit papillomavirus L1 protein provides complete protection against papillomavirus-induced disease. J. Virol. 76, 8900-8909 (2002).

89. Baud, D. et al. Immunogenicity against human papillomavirus type 16 virus-like particles is strongly enhanced by the PhoPc phenotype in Salmonella enterica serovar Typhimurium. Infect. Immun. 72, 750-756 (2004)

90. Baud, D. Ponci, F., Bobst, M., De Grandi, P. \& Nardelli-Haefliger, D. Improved efficiency of a Salmonella-based vaccine against human papillomavirus type 16 virus-like particles achieved by using a codon-optimized version of L1 . J. Virol. 78, 12901-12909 (2004).

91. Gillison, M. L. et al. Evidence for a causal association between human papillomavirus and a subset of head and neck cancers. J. Natl Cancer Inst. 92, 709-720 (2000).

92. Garnett, G. P. Role of herd immunity in determining the effect of vaccines against sexually transmitted disease. J. Infect. Dis. 191 Suppl. 1, S97-S106 (2005).

93. Taira, A. V., Neukermans, C. P. \& Sanders, G. D. Evaluating human papillomavirus vaccination programs. Emerg. Infect. Dis. 10, 1915-1923 (2004)

94. Clifford, G. M. et al. Cancer risk in the Swiss HIV Cohort Study: associations with immunodeficiency, smoking, and highly active antiretroviral therapy. J. Natl Cancer Inst. 97, 425-432 (2005).

95. Bhatia, S. et al. Solid cancers after bone marrow transplantation. J. Clin. Oncol. 19, 464-471 (2001).

96. Cornejo-Juarez, P. et al. Randomized controlled trial of Hepatitis B virus vaccine in HIV-1-infected patients comparing two different doses. AIDS Res. Ther. 3, 9 (2006)

97. de Melo-Martin, I. The promise of the human papillomavirus vaccine does not confer immunity against ethical reflection. Oncologist 11, 393-396 (2006). 
98. Zimmerman, R. K. Ethical analysis of HPV vaccine policy options. Vaccine (2006)

99. Winer, R. L. et al. Condom use and the risk of genital human papillomavirus infection in young women. N. Engl J. Med. 354, 2645-2654 (2006).

100. Castellsague, X. et al. Male circumcision, penile human papillomavirus infection, and cervical cancer in female partners. N. Engl. J. Med. 346, 1105-1112 (2002).

101. Steinbrook, R. The potential of human papillomavirus vaccines. N. Engl. J. Med. 354, 1109-1112 (2006).

102. Anhang, R., Wright, T. C. Jr, Smock, L. \& Goldie, S. J. Women's desired information about human papillomavirus. Cancer 100, 315-320 (2004).

103. Garnett, G. P. \& Waddell, H. C. Public health paradoxes and the epidemiological impact of an HPV vaccine. J. Clin. Virol. 19, 101-111 (2000)

104. Hughes, J. P., Garnett, G. P. \& Koutsky, L. The theoretical population-level impact of a prophylactic human papilloma virus vaccine. Epidemiology 13 631-639 (2002)

105. Franco, E. L., Rohan, T. E. \& Villa, L. L. Epidemiologic evidence and human papillomavirus infection as a necessary cause of cervical cancer. J. Natl Cancer Inst. 91, 506-511 (1999)

106. McCance, D. J. Human papillomaviruses and cell signaling. Sci. STKE 2005, pe29 (2005)

107. Munger, K. et al. Mechanisms of human papillomavirus-induced oncogenesis. J. Virol. 78, 11451-11460 (2004).

108. Brandsma, J. L. Animal models of humanpapillomavirus-associated oncogenesis. Intervirology 37, 189-200 (1994)

109. Walboomers, J. M. et al. Human papillomavirus is a necessary cause of invasive cervical cancer worldwide. J. Pathol. 189, 12-19 (1999).

This worldwide survey found HPV DNA in $99.7 \%$ of cervical cancers, indicating that HPV is a necessary cause of cervical cancer.
110. Meyers, C., Frattini, M. G., Hudson, J. B. \& Laimins, L. A. Biosynthesis of human papillomavirus from a continuous cell line upon epithelial differentiation. Science 257, 971-973 (1992).

111. Hawley-Nelson, P., Vousden, K. H., Hubbert, N. L. Lowy, D. R. \& Schiller, J. T. HPV 16 E6 and E7 proteins cooperate to immortalize human foreskin keratinocytes. EMBO J. 8, 3905-3910 (1989).

112. Goodwin, E. C. et al. Rapid induction of senescence in human cervical carcinoma cells. Proc. Natl Acad. Sci. USA 97, 10978-10983 (2000).

113. Rous, P. \& Beard, J. W. The progression to carcinoma of virus induced rabbit papillomas (Shope). J. Exp. Med. 62, 523-545 (1935)

A description of the rabbit papillomavirus model of squamous cancer.

114. Durst, M., Bosch, F. X., Glitz, D., Schneider, A. \& zur Hausen, $\mathrm{H}$. Inverse relationship between human papillomavirus (HPV) type 16 early gene expression and cell differentiation in nude mouse epithelial cysts and tumors induced by HPV-positive human cell lines. J. Virol. 65, 796-804 (1991).

115. Kirnbauer, R. et al. A virus-like particle enzyme-linked immunosorbent assay detects serum antibodies in a majority of women infected with human papillomavirus type 16. J. Natl Cancer Inst. 86, 494-499 (1994).

The first description of the VLP ELISA and the presence of L1 VLP-specific antibodies in sera obtained from cervical cancer patients.

116. Ekalaksananan, T. et al. Usefulness of combining testing for $\mathrm{p} 16$ protein and human papillomavirus (HPV) in cervical carcinoma screening. Gynecol. Oncol. (2006).

117. US Food and Drug Administration. New Device Approval-Digene Hybrid Capture 2 High-Risk HPV DNA Test- P890064 S009 A004. US Food and
Drug Administration [online], http://www.fda.gov/ cdrh/mda/docs/p890064s009.html (2003).

118. Gravitt, P. E. et al. Evaluation of self-collected cervicovaginal cell samples for human papillomavirus testing by polymerase chain reaction Cancer Epidemiol. Biomarkers Prev. 10, 95-100 (2001).

Acknowledgements

We thank R. Calizo for help with artwork as well as J. T. Schiller, R. J. Kurman, B. M. Ronnett, R. P. Viscidi, P. Gravitt and R. Hruban for critically reading our manuscript R. B. S. R. and T.-C. W. are supported by the National Cancer Insititute SPORE in Cervical Cancer, and R. B. S. R. is supported by an American Cancer Society Research Scholar Grant.

\section{Competing interests statement}

The authors declare competing financial interests: see web version for details.

DATABASES

The following terms in this article are linked online to:

National Cancer Institute: http://www.cancer gov anal cancer / cervical cancer | head and neck cancer oral cancer | oropharyngeal cancer | penile cancer

vulvar cancer

FURTHER INFORMATION

The laboratory of T.-C. Wu: http://pathology2.jhu.edu/tclab/ home.cfm

Surveillance Epidemiology and End Results: http://seer.

cancer.gov

WHO: http://www.who.int

GAVI: http://www.gavialliance.org

FDA: http://www.fda.gov

Access to this links box is available online. 